\title{
Medical uses of Commiphora Wightii
}

\author{
Sakshi Jaiswal ${ }^{1}$ JyotiKiran Bara ${ }^{2}$, Ritu Soni ${ }^{3}$, Dr.Parul Saksena ${ }^{4}$ \\ Department of Biotechnology,SriSathyaSai College Bhopal,(M.P) India
}

\begin{abstract}
The plant Commiphorawightii has vast economic value and a wide array of medicinal uses in both ancient and modern therapeutics. The plant medicinally important natural gum resin.Guggul was first introduced to scientific world by an Indian Medical Researcher, G.V Satyavati in 1966. Commiphorawightii, guggulu, has emerged as a good source of the traditional medicines for the treatment of inflammation, arthritis, obesity, microbial infection, wound, pain, fractures, tumor, and gastrointestinal diseases. It is one of the oldest and the most prominent herbs in Ayurvedic medicine. Guggulu is a versatile drug and, because of its paranormal properties, it is very valuable in treating variety of disorders. Pharmacological results have validated the use of this plant in the traditional medicines. This plant contains a number of bioactive constituents including terpenoids, steroids, flavonoids, guggultetrols, lignans, sugars, and amino acids. Guggulsterones $E$ and $Z$ are the chief bioactive constituents of this resin and are endowed with immense pharmacological value. These conclusions could open a new window on the use of this plant in Ayurveda. This review clearly authenticates the Sanskrit definition of the term "guggul" which means one that protects against diseases. It is superbly reflected and proved by the diverse medicinal uses of this Ayurvedic drug. This plant still possesses an unexplored potential and expansion of research materials would provide more opportunities for the discovery of novel bioactive principles from this plant.
\end{abstract}

Keywords: Commophora Wightii, Ayurvedic drug, Oleo-gum resin, Cholesterolemic, Guggulsterone

\section{Introduction}

Guggulu consists of oleo-gum resin obtained as an exudate from the tapping of stem and branches of Commiphorawightii (Arnott) Bhandari [syn. Commiphoramukul (Hook. Ex Stocks) Engl; Balsamodendronmukul (Hook.Ex Stocks); Family, Burseraceae]. The plant is commonly known as guggul tree and is found in arid areas of India, Bangladesh, and Pakistan. In India, it is found in Rajasthan, Gujarat, Assam, Madhya Pradesh, and Karnataka. It is a small, bushy tree with thorny branches and produces a yellowish gum resin (guggulu) in small ducts located throughout its bark. The trees are tapped by making an incision on the bark. The resin, which flows out, is allowed to harden before it is collected. The tree is tapped from November to January and the resin is collected through May to June. A guggul tree yields between 250 to $500 \mathrm{~g}$ of dry resin during each collection season $[1,2]$.

In Indian traditional system of medicine, guggulu has been used for thousands of years in the treatment of arthritis, inflammation, gout, rheumatism, obesity, and disorders of lipids metabolism [3]. It is known by different names like guggula, guggul, guggal, gugar, and Indian bdellium [4]

Guggulu occurs in vermicular pieces of pale yellow or brown coloured mass with aromatic odour and bitter astringent taste; when fresh it is viscid and golden coloured. It should produce not more than 5 percent of total ash and 1 percent of acid-insoluble ash. It yields not less than 27 percent of alcohol-soluble matter and not less than 53 percent of water-soluble matter. The genuine samples of guggulu contain 1 percent of volatile oil [2] and between 1.0 and 1.5 percent of guggulsterones ( $Z$ and $E)$ [3].

Guggulu Shodhana (shodhanvidhi). It has been mentioned in Ayurvedic texts that administration of raw guggulu may lead to skin rashes, irregular menstruation, diarrhoea, headache, mild nausea, and, with very high doses, liver toxicity [5]. In order to overcome unwanted effects of raw guggulu, Ayurveda describes a number of purification processes (shodhanvidhi) using different fluids (dravyas), which not only take care of the adverse effects but also enhance the therapeutic activity. According to Ayurvedic texts, guggulu must be purified before incorporating into formulations [1]. During a process of shodhan, guggulu is treated with specific materials of biological origin, for example, herbal juices, cow urine, and cow milk. It is possible that some of the properties (chemical and biological) of shodhan materials are added to guggulu during the purification process. It is also possible that some of the toxic or harmful constituents of raw guggulu are neutralized, detoxified, or removed during this process.

There are a large number of commercial polyherbal anti-inflammatory formulations which are using guggulu as the chief ingredient [6]. However, no study has been done to investigate the process of Ayurvedic purification and its probable effect on therapeutic efficacy except for one report which states that gastric irritancy of guggulu is reduced with purification [7]. 
During the process of purification, foreign matter is removed from raw guggulu manually and is then broken into small pieces. The broken mass is wrapped in a piece of cloth (called potli) and hanged into an inert container (called dolayantra) containing one of the recommended media which are gomutra (cow urine), triphalakasaya (decoction of triphala), vasapatrakasaya (decoction of Adhatodavasica leaves), vasapatrasavrasa (aqueous extract of Adhatodavasica leaves), dugdha (milk), and water. The guggulu is kept immersed, while fluid is boiled till all the soluble matter of guggulu is dissolved in the purifying vehicle. The insoluble part of guggulu is taken out and discarded. Further boiling is continued till guggulu solution forms a soft mass. It is then poured out over a smooth wooden board smeared with cow ghee or castor oil and dried in the sun. The dried mass is called purified guggulu (suddhguggulu) [1].

\section{Medical use- \\ Traditional Uses of Guggulu}

Guggulu has a long history of use in Ayurveda. The Atharvaveda is the earliest reference containing its medicinal and therapeutic properties [29]. Detailed description regarding its actions, uses, and indications and the varieties of guggul have been described in numerous Ayurvedic treatises including CharakaSamhita (1000 B.C.), SushrutaSamhita (600 B.C.) and Vagbhata (7th century A.D.). In addition, various medical lesions were written between the 12th and 14th centuries A.D. [30]. Guggulu has been used to treat obesity, osteoarthritis, rheumatoid arthritis, gout, facial paralysis, sciatica, constipation, haemorrhoids, liver disorders, inflammation, cyst, cervical lymphadenitis, coronary thrombosis, anaemia, diabetes, urinary calculus, increased frequency and turbidity of urine, and skin diseases [31,32].

It has a wide range of usefulness in indigenous medicine. It is astringent and antiseptic and acts as a bitter, stomachic, and carminative when taken internally. Like all oleo resins, it causes increase in number of leucocytes and stimulates phagocytosis. It acts as a diaphoretic, expectorant, diuretic, uterine stimulant, and emmenagogue. The resin is used in the form of lotion for indolent ulcers and as a gargle in caries, spongy gums, pyorrhea, chronic tonsillitis, and ulcerated throat. Inhalation of the fumes from burnt guggulu is recommended in hay fever, acute and chronic nasal catarrh, chronic laryngitis, chronic bronchitis, and phthisis. It is an ingredient of ointment for ulcers [2].

\section{Pharmacological Activity of Guggulu Hypolipidemic Activity}

The lipid lowering effect of guggulu with special reference to atherosclerosis and obesity (medoraga) was first reported in a doctorate thesis submitted to the Banaras Hindu University (BHU) in January 1966. Earlier to this work, guggulu was well known as an Ayurvedic drug for the treatment of various types of arthritis. This work was inspired by a rather obscure shloka in Sanskrit in the well-known Ayurvedic treatise SushrutaSamhita. The shloka deals in an extraordinarily lucid and scientific manner, with the etiology, pathogenesis, and treatment of obesity and associated lipid disorders and their complications. The hypolipidemic activity was shown in animals as well as in patients of obesity and hypercholesterolemia [33].

In carefully planned studies carried out (over a period of two years) on rabbits, in which hyperlipidemia was induced by feeding cholesterol (in hydrogenated vegetable oil), it was demonstrated for the very first time that crude guggulu could not only lower significantly the serum cholesterol in hypercholesterolemic rabbits but also protected these animals against cholesterol-induced atherosclerosis at the fatty streak stage. It also reduced the body weight of the animals. A similar trend to reduce significantly the serum cholesterol levels in patients with obesity and hypercholesterolemia was found in clinical studies with crude guggulu. The Central Drug Research Institute (CDRI), Lucknow, has been engaged in chemical, pharmacological, and clinical studies on guggulu [33].

Gugulipid, an ethyl acetate extract of the oleoresin, standardized at CDRI, has been marketed in India since 1988 as a hypolipidemic agent. It contains Z-guggulsterones and E-guggulsterones which are purported to be the compounds responsible for the hypolipidemic activity of the guggulu [34, 35]. Gugulipid contains not less than 4 percent and not more than 6 percent of guggulsterones (Zand E). The decision to use the ethyl acetate extract rather than two guggulsterones was primarily for commercial reasons and was also because of the fact that other components of the ethyl acetate extract showed synergistic (hypolipidemic) effect [33]. A number of clinical studies were carried out to confirm hypolipidemic activity of guggulu and gugulipid [36, 37]. The findings of multicentric clinical trials carried out with gugulipid at seven different centres in India coordinated in collaboration with CDRI confirmed the role of gugulipid as a hypolipidemic agent [36].

The hypolipidemic activity of guggulu and its various fractions has been studied in several animal models and clinical studies [1]. Initial studies reported that crude guggulu has encouraging hypolipidemic activity in rabbits [38]. This activity was also confirmed in other animals including white leghorn chicks, domestic pig, Presbytis monkey, and albino rat [1]. 


\section{Thyroid Stimulatory Activity}

Administration of ethanolic extract of guggulu to the female albino mice for 15 days enhanced the triiodothyonine (T3) concentration and T3/T4 ratio, while no marked change in the concentrations of serum thyroxine (T4) was observed [47]. Z-Guggulsterone was shown to be responsible for the thyroid stimulatory action of guggulu. Administration of isolated Z-guggulsterone to rats led to significant increase in all thyroid function parameters, namely, uptake of iodine by the thyroid, enzymes involved in the synthesis of thyroid hormones, and tissue oxygen uptake, thus suggesting thyroid stimulatory action [48].

\section{Anti-Inflammatory and Antiarthritic Activity}

The results of several studies confirm anti-inflammatory and antiarthritic activities of guggulu [13, 15, 25, 49-52]. The 50 percent aqueous methanolic extract was found to exhibit an anti-inflammatory effect on adjuvant-induced air pouch granuloma in mice. The methanolic extract inhibited nitric oxide production in lipopolysaccharide activated mouse peritoneal macrophages [15]. A crystalline steroid was isolated from the petroleum ether extract and tested in rats for inhibition of inflammation induced by Freund's adjuvant. It inhibited the full development of the primary lesions in adjuvant arthritis and also reduced the severity of secondary lesions as compared with the untreated control group [53].

Guggulosomes prepared using guggul with ibuprofen by bath sonication and trituration methods were studied for anti-inflammatory activity. It was clearly shown that guggulosomes had more efficacy than ibuprofen and both guggul and ibuprofen had synergistic effect. The study proved that guggul could serve as a carrier for entrapping drugs and for their sustained release action [54].

Several animal studies have demonstrated the effectiveness of guggulu extract in standard osteoarthritis (OA) models. The authors had conducted both animal and clinical investigations of guggulu for OA prior to this study. The goal of this study was to determine the effectiveness of guggulu for reduction of pain, stiffness, and other symptoms that arise from OA [55].

\section{Antioxidant Activity}

The antioxidant property of guggulu helped stop the oxidation of cholesterol and subsequent hardening of the arteries, reduced the stickiness of platelet, and also lowered the risk of coronary artery disease [45]. It also enhanced the production of thyroxin and triiodothyronine; these hormones increase the metabolism of carbohydrates and protein synthesis and help in lowering the lipid activity [47].

The antioxidant activity was attributed to the presence of guggulsterones. It was tested in vitro against the formation of oxygen free radicals. The oxidation of human LDL induced by $\mathrm{Fe} 2+$ or by rat peritoneal macrophages caused marked formation of lipid peroxidation products. Guggulsterone $(50 \mu \mathrm{M})$ prevented the generation of thiobarbituric acid reactive substances and lipid hydroperoxide of low density lipoprotein in above system. However, it did not protect lipids against the formation of conjugated dienes, the initial step of lipid peroxidation cascade. Guggulsterone significantly inhibited the reaction of lipid peroxidation in liver microsomes challenged with $\mathrm{Fe} 2+$ and sodium ascorbate. Thus, the protective action of guggulsterone might also be due to free radical scavenging property. The metal chelating capacity of guggulsterone might be contributing to its antioxidant activity [56]. Also, the alcoholic extract of C. mukul exhibited antioxidant property [57].

\section{Antiatherosclerotic Activity}

LDL has been found to accumulate in atherosclerotic lesions and is the major source of the cholesterol accumulation in human foam cells. There is evidence that LDL oxidation is essential for atherogenesis and the antioxidants that prevent this oxidation may either slow down or prevent atherogenesis. Guggulsterones, the lipid-lowering components of guggulu, effectively inhibited in vitro LDL oxidation (as discussed under antioxidant action). Thus the combination of antioxidant and lipid-lowering properties of guggulu makes it especially beneficial against atherogenesis [58].

\section{Cardioprotective Activity}

Guggulsterones are shown to be effective cardioprotectives. Myocardial necrosis induced by isoproterenol in rats caused marked increase in serum creatine phosphokinase and glutamate pyruvate transaminase. Phospholipase, xanthine oxidase, and lipid peroxides were simultaneously enhanced in ischemic heart following depletion of glycogen, phospholipids, and cholesterol. Treatment with guggulsterone at a dose of $50 \mathrm{mg} / \mathrm{kg}$ significantly protected cardiac damage as assessed by the reversal of blood and heart biochemical parameters in ischemic rats [59].

\section{Cytotoxic Activity}

Ferulates, important bioactive constituents identified from the guggulu gum, were reported to play a significant role in in vitro cytotoxicity by decreasing the cell viability in MCF-7 (breast) tumor cells, PC-3 
(prostate) tumor cells, and parental and transfected P 388 cells [49]. Therefore, ferulate compounds are used in the method for prevention and treatment of abnormal cell growth and proliferation of inflammation, neoplasia, and cardiovascular disease. Ethyl acetate extract showed significant in vitro cytotoxicity. A fraction showing cytotoxic activity was characterized as a mixture of two ferulates with an unusual skeleton by spectral and chemical methods. This fraction also showed moderate scavenging effect against 2,2-diphenyl-1-picryl hydrazyl $(\mathrm{DPPH})$ radicals [60].

Treatment with gugulipid significantly inhibited the viability of human prostate cancer cell line LNCaP (androgen-dependent) and its androgen-independent variant (C-81) with IC50 of $1 \mu \mathrm{M}$ (24 h treatment), thus indicating its possible role in apoptosis and cancer prevention [60]. The results of this study indicated that guggulsterone inhibited proliferation of PC-3 cells in culture by causing apoptosis, whereas a normal prostate epithelial cell line is resistant to growth inhibition and apoptosis induction by this phytoconstituent. These observations provided rationale for further preclinical and clinical evaluation of guggulsterone for its efficacy against prostate cancer [61]

\section{Antifertility Activity}

Guggulu administered orally ( 2 and $20 \mathrm{mg} / 100 \mathrm{~g}$ body weight) to female rats decreased the weight of the uterus, ovaries, and cervix, whereas glycogen and sialic acid levels in these organs increased. This suggested that guggulu may be useful as an antifertility agent [62].

\section{Skin Diseases}

Administration of gugulipid was reported to be effective in the treatment of nodulocystic acne. A study in 21 patients found that gugulipid was as effective as tetracycline in the treatment. The patients with oily faces responded better to the gugulipid treatment [63].

\section{Antimicrobial Activity}

The volatile oil of $\mathrm{C}$ mukul was found to be highly effective against Rhyzoperthadominica which suggested its role as a fumigant. The ethanolic extract of $\mathrm{C}$. mukul exhibited best antibacterial activity at $5 \mathrm{mg} / \mathrm{mL}$ against multidrug-resistant Klebsiella pneumonia [65]. An active compound, 5(1-methyl,1aminoethyl)-5-methyl-2-octanone, of the methanolic extract of guggulu gum possessed significant antibacterial activity against Gram-positive bacteria and moderate activity against Gram-negative bacteria [66-68].

\section{Conclusions}

From this review article it is concluded that the resin of Commiphorawightii, guggulu, has emerged as a good source of the traditional medicines for the treatment of inflammation, arthritis, obesity, microbial infection, wound, pain, fractures, tumor, and gastrointestinal diseases. It is one of the oldest and the most prominent herbs in Ayurvedic medicine. Guggulu is a versatile drug and, because of its paranormal properties, it is very valuable in treating variety of disorders. Pharmacological results have validated the use of this plant in the traditional medicines. This plant contains a number of bioactive constituents including terpenoids, steroids, flavonoids, guggultetrols, lignans, sugars, and amino acids. Guggulsterones $\mathrm{E}$ and $\mathrm{Z}$ are the chief bioactive constituents of this resin and are endowed with immense pharmacological value. These conclusions could open a new window on the use of this plant in Ayurveda. This review clearly authenticates the Sanskrit definition of the term "guggul" which means one that protects against diseases. It is superbly reflected and proved by the diverse medicinal uses of this Ayurvedic drug.

In vitro studies and clinical trials help improve and advance medical care. They also assist health care professionals to direct resources to the strategies and treatments that would work best for a particular type of ailment. Although the use of guggulu in therapeutic doses appears to be safe and nontoxic more and more of such studies should still be conducted so that chances of any toxicity, if any, can be ruled out. It has also been mentioned that during the course of using guggulu one should avoid foods that are sour or bitter in taste, alcohol, excessive exercise, physical and mental strain, anger, and exposure to direct sunlight. Such data can only be validated when we would choose in vitro studies over in vivo studies.

Also, this plant is listed in IUCN list and thus rationale usage of the plant is the need of the hour so that we do not end up depleting this wonder drug of high therapeutic importance. Keeping this in view, stem, bark, and leaf of this plant should receive more attention so that the complete depletion on account of plant death due to tapping can be checked. This plant still possesses an unexplored potential and expansion of research materials would provide more opportunities for the discovery of novel bioactive principles from this plant.

\section{References}

[1]. The Ayurvedic Pharmacopoeia of India (Formulations) 1st. New Delhi, India: Department of Indian Systems of Medicine and Homeopathy, Ministry of Health and Family Welfare, Government of India; 2007. 
[2]. The Ayurvedic Pharmacopoeia of India. 1st. New Delhi, India: Department of Indian Systems of Medicine and Homeopathy, Ministry of Health and Family Welfare, Government of India; 2001.

[3]. Urizar N. L., Moore D. D. Gugulipid: a natural cholesterol-lowering agent. Annual Review of Nutrition. 2003;23:303-313. doi: 10.1146/annurev.nutr.23.011702.073102. [PubMed] [Cross Ref]

[4]. Indian Pharmacopoeia. New Delhi, India: The Controller of Publications; 1996.

[5]. Masten S. A. Gum Guggul and Some of Its Steroidal Constituents: Review of Toxicological Literature. Vol. 2. Durham, NC, USA: US Department of Health and Human Services, National Toxicology Program (NTP), National Institute of Environmental Health Sciences (NIEHS), National Institutes of Health; 2005.

[6]. Karan M., Kumar V., Suneja V., Vasisht K. Commercial herbal anti-inflammatory formulations-a survey. Pharmacos. 2009;36:14-25.

[7]. Sangle V. D., Nadkarni S. D., Vahalia M. K., Darp M. S. The study of effect of ayurvedic processing of Commiphorawightii on gastric irritancy index in experimental animals. Indian Drugs. 2004;41(5):268-271.

[8]. Bhati A. Essential oil from the resin of Commiphoramukul, Hook. Ex. stocks.Journal of the Indian Chemical Society.1950;27:436440 .

[9]. Saxena V. K., Sharma R. N. Constituents of the essential oil from Commiphoramukul gum resin. Journal of Medicinal and Aromatic Plant Sciences. 1998;20:55-56.

[10]. Rücker G. Monocyclic diterpenes from Indian gugul resin (Commiphoramukul) Archiv der Pharmazie. 1972;305(7):486-493. doi: 10.1002/ardp.19723050703. [PubMed] [Cross Ref]

[11]. Prasad R. S., Dev S. Chemistry of ayurvedic crude drugs-IV: guggulu (resin from commiphoramukul - 4 absolute stereochemistry of mukulol. Tetrahedron. 1976;32(12):1437-1441. doi: 10.1016/0040-4020(76)85026-0. [Cross Ref]

[12]. Patil V. D., Nayak U. R., Dev S. Chemistry of ayurvedic crude drugs-II. Guggulu (resin from Commiphoramukul)-2: diterpenoid constituents. Tetrahedron. 1973;29(2):341-348. doi: 10.1016/s0040-4020(01)93299-5. [Cross Ref]

[13]. Francis J. A., Raja S. N., Nair M. G. Bioactive terpenoids and guggulusteroids from Commiphoramukul gum resin of potential antiinflammatory interest. Chemistry and Biodiversity. 2004;1(11):1842-1853. doi: 10.1002/cbdv.200490138. [PubMed] [Cross Ref]

[14]. Matsuda H., Morikawa T., Ando S., et al. Absolute stereostructures of polypodane-type triterpenes, myrrhanol A and myrrhanone A, from guggul-gum resin (the resin of Balsamodendronmukul) Chemical and Pharmaceutical Bulletin. 2004;52(10):1200-1203. doi: 10.1248/cpb.52.1200. [PubMed] [Cross Ref]

[15]. Kimura I., Yoshikawa M., Kobayashi S., et al.New triterpenes, myrrhanol A and myrrhanone A, from guggul-gum resins, and their potent anti-inflammatory effect on adjuvant-induced air-pouch granuloma of mice.Bioorganic and Medicinal Chemistry Letters. 2001;11(8):985-989. doi: 10.1016/s0960-894x(01)00111-1. [PubMed] [Cross Ref]

[16]. Xu J., Guo Y., Zhao P., et al. Neuroprotectivecadinanesesquiterpenes from the resinous exudates of Commiphoramyrrha. Fitoterapia. 2011;82(8):1198-1201. doi: 10.1016/j.fitote.2011.08.001. [PubMed] [Cross Ref]

[17]. Hanus L. O., Rezankab T., Dembitskya V. M., Moussaieffa A. Myrrh-Commiphora chemistry. Biomedical Papers. 2005;149(1):3-28. [PubMed]

[18]. Patil V. D., Nayak U. R., Dev S. Chemistry of Ayurvedic crude drugs-I: Guggulu (resin from Commiphoramukul)—1: steroidal constituents. Tetrahedron. 1972;28(8):2341-2352. doi: 10.1016/s0040-4020(01)93577-x. [Cross Ref]

[19]. Purushothaman K. K., Chandrasekharan S. Guggulsterols from Commiphoramukul (Burseraceae) Indian Journal of Chemistry Section B. 1976;14:802-804.

[20]. Bajaj A. G., Dev S. Chemistry of ayurvedic crude drugs-V. Guggulu (resin from Commiphoramukul)—5 some new steroidal components and, stereochemistry of guggulsterol-I at C-20 and C-22. Tetrahedron. 1982;38(19):2949-2954. doi: 10.1016/00404020(82)85024-2. [Cross Ref]

[21]. Fatope M. O., Al-Burtomani S. K. S., Ochei J. O., Abdulnour A. O., Al-Kindy S. M. Z., Takeda Y. Muscanone: a 3-O-(1",8",14"trimethylhexadecanyl) naringenin from Commiphorawightii. Phytochemistry. 2003;62:1251-1255. [PubMed]

[22]. Kakrani H. K. Flavonoids from the flowers of Commiphoramukul. Fitoterapia. 1981;52(5):221-223.

[23]. Kumar V., Dev S. Chemistry of ayurvedic crude drugs-VII guggulu (resin from Commiphoramukul) -6: absolute stereochemistry of guggultetrols. Tetrahedron. 1987;43(24):5933-5948. doi: 10.1016/s0040-4020(01)87799-1. [Cross Ref]

[24]. Su S.-L., Duan J.-A., Tang Y.-P., et al. Isolation and biological activities of neomyrrhaol and other terpenes from the resin of Commiphoramyrrha. PlantaMedica. 2009;75(4):351-355. doi: 10.1055/s-0028-1112214. [PubMed] [Cross Ref]

[25]. Matsuda H., Morikawa T., Ando S., et al. Absolute stereostructures of polypodane- and octanordammarane-type triterpenes with nitric oxide production inhibitory activity from guggul-gum resins. Bioorganic and Medicinal Chemistry. 2004;12(11):3037-3046. doi: 10.1016/j.bmc.2004.03.020. [PubMed] [Cross Ref]

[26]. Bose S., Gupta K. C. Structure of Commiphoramukul gum I: nature of sugars present and the structure of aldobiouronic acid. Indian Journal of Chemistry Section A. 1966;2:57-60.

[27]. Ali M. A., Hasan M. Chemical investigation of Commiphoramukul Engl. (Burseraceae) Pakistan Journal of Scientific and Industrial Research. 1967;10:21-23.

[28]. Satyavati G. V. Guggulipid: a promising hypolipidemic agent from gum guggul (Commiphorawightii) Economic and Medicinal Plant Research. 1991;5:48-82.

[29]. SushrutaSamhita. chapter 15. Varanasi, India: Chowkamba Sanskrit Sirija; 1954.

[30]. Pandey G. DravyagunaVijnana. 2nd. Varanasi, India: ChaukhamblaOrientalia; 2004.

[31]. Dev S. A modern look at an age old ayurvedic drug guggulu.Science Age. 1987;5:13-18

[32]. Anurekha J., Gupta V. B. Chemistry and pharmacological profile of guggulu—a review. Indian Journal of Traditional Knowledge. 2006;5:478-483.

[33]. Satyavati G. V. Gum guggul (Commiphoramukul) - the success story of an ancient insight leading to a modern discovery. Indian Journal of Medical Research. 1988;87(4):327-335. [PubMed]

[34]. de Morais S. M., Facundo V. A., Bertini L. M., et al. Chemical composition and larvicidal activity of essential oils from piper species. Biochemical Systematics and Ecology. 2007;35(10):670-675. doi: 10.1016/j.bse.2007.05.002. [Cross Ref]

[35]. Sahni S., Hepfinger C. A., Sauer K. A. Guggulipid use in hyperlipidemia: case report and review of the literature. American Journal of Health-System Pharmacy. 2005;62(16):1690-1692. doi: 10.2146/ajhp040580. [PubMed] [Cross Ref]

[36]. Nityanand S., Srivastava J. S., Asthana O. P. Clinical trials with gugulipid-a new hypolipidaemic agent. The Journal of the Association of Physicians of India. 1989;37(5):323-328. [PubMed]

[37]. Verma S. K., Bordia A. Effect of Commiphoramukul (gum guggulu) in patients of hyperlipidemia with special reference to HDLcholesterol. Indian Journal of Medical Research. 1988;87(4):356-360. [PubMed]

[38]. Satyavati G. V., Dwarakanath C., Tripathi S. N. Experimental studies on the hypocholesterolemic effect of Commiphoramukul. The Indian Journal of Medical Research. 1969;57(10):1950-1962. [PubMed] 
[39]. Baldwa V., Bhasin V., Ranka P., Mathur K. Effects of Commiphoramukul (guggulu) in experimentally induced hyperlipemia and atherosclerosis. The Journal of the Association of Physicians of India. 1981;29(1):13-17. [PubMed]

[40]. Hasani R. S., Nayebi N., Moradi L., Mehri A., Larijani B., Abdollahi M. The efficacy and safety of herbal medicines used in the treatment of hyperlipidemia; a systematic review.Current Pharmaceutical Design. 2010;16(26):2935-2947. doi: 10.2174/138161210793176464. [PubMed] [Cross Ref]

[41]. Chander R., Khanna A. K., Kapoor N. K. Lipid lowering activity of guggulsterone from Commiphoramukul in hyperlipaemic rats. Phytotherapy Research. 1996;10(6):508-511.

[42]. Wu J., Xia C., Meier J., Li S., Hu X., Lala D. S. The hypolipidemic natural product guggulsterone acts as an antagonist of the bile acid receptor. Molecular Endocrinology. 2002;16(7):1590-1597. doi: 10.1210/me.16.7.1590. [PubMed] [Cross Ref]

[43]. Urizar N. L., Liverman A. B., Dodds D. T., et al. A natural product that lowers cholesterol as an antagonist ligand for FXR.Science. 2002;296(5573):1703-1706. doi: 10.1126/science.1072891. [PubMed] [Cross Ref]

[44]. Yu B.-Z., Kaimal R., Bai S., et al. Effect of guggulsterone and cembranoids of Commiphoramukul on pancreatic phospholipase A2 role in hypocholesterolemia. Journal of Natural Products. 2009;72(1):24-28. doi: 10.1021/np8004453. [PubMed] [Cross Ref]

[45]. Mester L., Mester M., Nityanand S. Inhibition of platelet aggregation by 'guggulu' steroids. PlantaMedica. 1979;37(4):367-369. doi: 10.1055/s-0028-1097351. [PubMed] [Cross Ref]

[46]. Bordia A., Chuttani S. K. Effect of gum guggula on fibrinolysis and platelet adhesiveness in coronary heart disease. Indian Journal of Medical Research. 1979;70(6):992-996. [PubMed]

[47]. Panda S., Kar A. Gugulu (Commiphoramukul) induces triiodothyronine production: possible involvement of lipid peroxidation. Life Sciences. 1999;65(12):137-141. doi: 10.1016/s0024-3205(99)00369-0. [PubMed] [Cross Ref]

[48]. Tripathi Y. B., Malhotra O. P., Tripathi S. N. Thyroid stimulating action of Z-guggulsterone obtained from Commiphoramukul. PlantaMedica. 1984;50(1):78-80. doi: 10.1055/s-2007-969626. [PubMed] [Cross Ref]

[49]. Chaudhary G. Pharmacological properties of CommiphorawightiiArn.Bhandari—an overview.International Journal of Pharmacy and Pharmaceutical Sciences. 2012;4(3):73-75.

[50]. Gujral M. L., Sareen K., Tangri K. K., Amma M. K., Roy A. K. Antiarthritic and anti-inflammatory activity of gum guggul (Balsamodendronmukul Hook) Indian Journal of Physiology and Pharmacology. 1960;4:267-273. [PubMed]

[51]. Khanna D., Sethi G., Ahn K. S., et al. Natural products as a gold mine for arthritis treatment. Current Opinion in Pharmacology. 2007;7(3):344-351. doi: 10.1016/j.coph.2007.03.002. [PubMed] [Cross Ref]

[52]. Karan M., Sarup P., Suneja V., Vasisht K. Effect of traditional ayurvedic purification processes (sodhanvidhi) of guggulu on carrageenan-induced paw oedema in rats. Journal of Pharmaceutical and Biomedical Sciences. 2012;21(5):1-5.

[53]. Arora R. B., Taneja V., Sharma R. C., Gupta S. K. Anti-inflammatory studies on a crystalline steroid isolated from Commiphoramukul. Indian Journal of Medical Research. 1972;60(6):929-931. [PubMed]

[54]. Verma S., Jain A., Gupta V. B. Synergistic and sustained anti-inflammatory activity of guguul with the ibuprofen: a preliminary study. International Journal of Pharma and Bio Sciences. 2010;1:1-7.

[55]. Singh B. B., Mishra L. C., Vinjamury S. P., Aquilina N., Singh V. J., Shepard N. The effectiveness of Commiphoramukul for osteoarthritis of the knee: an outcomes study. Alternative Therapies in Health and Medicine. 2003;9(3):74-79. [PubMed]

[56]. Chander R., Khanna A. K., Pratap R. Antioxidant activity of guggulsterone, the active principle of guggulipid from Commiphoramukul. Journal of Medicinal and Aromatic Plant Sciences. 2002;24:371-375.

[57]. Bellamkonda R., Rasineni K., Singareddy S. R., et al. Antihyperglycemic and antioxidant activities of alcoholic extract of Commiphoramukul gum resin in streptozotocin induced diabetic rats. Pathophysiology. 2011;18(4):255-261. doi: 10.1016/j.pathophys.2010.10.002. [PubMed] [Cross Ref]

[58]. Wang X., Greilberger J., Ledinski G., Kager G., Paigen B., Jürgens G. The hypolipidemic natural product Commiphoramukul and its component guggulsterone inhibit oxidative modification of LDL. Atherosclerosis. 2004;172(2):239-246. doi: 10.1016/j.atherosclerosis.2003.10.008. [PubMed] [Cross Ref]

[59]. Chander R., Rizvi F., Khanna A. K., Pratap R. Cardioprotective activity of synthetic guggulsterone (E and Z-isomers) in isoproterenol induced myocardial ischemia in rats: a comparative study. Indian Journal of Clinical Biochemistry. 2003;18(2):71-79. [PMC free article] [PubMed]

[60]. Zhu N., Rafi M. M., DiPaola R. S., et al. Bioactive constituents from gum guggul (Commiphorawightii) Phytochemistry. 2001;56(7):723-727. doi: 10.1016/s0031-9422(00)00485-4. [PubMed] [Cross Ref]

[61]. Xiao D., Zeng Y., Prakash L., Badmaev V., Majeed M., Singh S. V. Reactive oxygen species-dependent apoptosis by gugulipid extract of ayurvedic medicine plant Commiphoramukul in human prostate cancer cells is regulated by c-Jun $\mathrm{N}$-terminal kinase. Molecular Pharmacology. 2011;79(3):499-507. doi: 10.1124/mol.110.068551. [PMC free article] [PubMed] [Cross Ref]

[62]. Amma M. K. P., Malhotra N., Suri R. K., Arya O. P., Dani H. M., Sareen K. Effect of oleoresin of gum guggul (Commiphoramukul) on the reproductive organs of female rat. Indian Journal of Experimental Biology. 1978;16(9):1021-1023. [PubMed]

[63]. Thappa D. M., Dogra J. Nodulocystic acne: oral gugulipid versus tetracycline. Journal of Dermatology. 1994;21(10):729-731. doi: 10.1111/j.1346-8138.1994.tb03277.x. [PubMed] [Cross Ref]

[64]. Sharma B., Salunke R., Srivastava S., Majumder C., Roy P. Effects of guggulsterone isolated from Commiphoramukul in high fat diet induced diabetic rats. Food and Chemical Toxicology. 2009;47(10):2631-2639. doi: 10.1016/j.fct.2009.07.021. [PubMed] [Cross Ref]

[65]. Sharma A., Kumar Patel V., Rawat S., Ramteke P., Verma R. Identification of the antibacterial component of some Indian medicinal plants against klebsiellapneumoniae. International Journal of Pharmacy and Pharmaceutical Sciences. 2010;2(3):123127.

[66]. Goyal P., Chauhan A., Kaushik P. Assessment of Commiphorawightii (Arn.) Bhandari (Guggul) as potential source for antibacterial agent. Journal of Medicine and Medical Sciences. 2010;1(3):71-75

[67]. Ishnava K. B., Mahida Y. N., Mohan J. S. S. In vitro assessments of antibacterial potential of Commiphorawightii (Arn.)Bhandari.gum extract. Journal of Pharmacognosy and Phytotherapy. 2010;2(7):91-96.

[68]. Romero C. D., Chopin S. F., Buck G., Martinez E., Garcia M., Bixby L. Antibacterial properties of common herbal remedies of the southwest. Journal of Ethnopharmacology. 2005;99(2):253-257. doi: 10.1016/j.jep.2005.02.028. [PubMed] [Cross Ref]

[69]. Nohr L. A., Rasmussen L. B., Straand J. Resin from the mukul myrrh tree, guggul, can it be used for treating hypercholesterolemia? A randomized, controlled study.Complementary Therapies in Medicine. 2009;17(1):16-22. doi: 10.1016/j.ctim.2008.07.001. [PubMed] [Cross Ref]

[70]. Szapary P. O., Wolfe M. L., Bloedon L. T., et al. Guggulipid for the treatment of hypercholesterolemia: a randomized controlled trial. Journal of the American MedicalAssociation. 2003;290(6):765-772. doi: 